very conservative, even though the correlation is statistically significant. Tentatively, however, it appears that each $\mathrm{S}$ maintained a relatively constant position within each condition.

The results of the present study, along with a critical review of the discrepant literature, suggest an interesting hypothesis for future investigation. It may be, at least in Colinus virginianius, that natural (selfpaced) termination of tonic immobility is a measure of not only the so-called state of analgesia, etc., associated with "animal hypnosis," but also freezing behavior subsequent to this state, in which the organism is more responsive to external stimulation. If the high correlation between the termination times of Ss under the two conditions of visual stimulation of the present study is replicated in the future, it would appear that important internal organismal factors are intimately linked with the termination of both measures of immobility. Research is now being planned to investigate this extremely speculative hypothesis in greater depth.

\section{REFERENCES}

BAYARD, J. The duration of tonic immobility in guinea pigs. Journal of Comparative \& Physiological Psychology, 1957, 50, 130-133. HOAGLAND, H. The mechanism of tonic immobility. Journal of General Psychology, $1928,1,426-427$.

LIBERSON, W. T. Prolonged hypnotic states with local signs induced in guinea pigs. Science, 1948, $108,40-41$.

LIBERSON, W. T., SMITH, R. W., \& STERN, A. Experimental studies of the prolonged "hypnotic withdrawal" in guinea pigs. Journal of Neuropsychiatry, 1961, 3, 28-34.

MOWRER, O. H. A note on the effect of repeated hypnotic stimulation. Journal of Abnormal \& Social Psy chology, 1932, 27, 60-62.

RATNER, S. C. Comparative aspects of hypnosis. In J. Gordon (Ed.), Handbook of clinical and experimental hypnosis. New York: McMillan, 1967. Pp. 550-587.

RATNER, S. C. Hypnotic reactions of rabbits. Psychological Reports, 1958, 4, 209-210.

RATNER, S.C., \& THOMPSON, R. W. Immobility reactions (fear) of domestic fowl as a function of age and prior experiences. Animal Behaviour, 1960, 8, 186-191.

\section{NOTES}

1. I am grateful to Dr. Stanley Ratner, Dr. Lauren Harris, Dan Gutkin, and the members of Psychology 802 for their help in the formulation of this study.

2. Ratner, S.C. Unpublished manuscript.

\title{
Escape and avoidance conditioning of responses in the plegic arm of stroke patients: A preliminary study
}

\section{LAURENCE P. INCE, Center for Learning Disabilities, Briarwood, N.Y. 11435}

Three patients with hemiplegia resulting from cerebrovascular accidents were treated with escape and avoidance conditioning techniques designed to increase responding in the affected upper extremity. Using forearm flexion as the critical response class, two $S$ s received escape conditioning and one $S$ received avoidance conditioning. One $S$ in the avoidance condition and one $S$ in the escape condition showed no significant increases in responding above baseline. Marked changes were recorded for the other $S$ in the escape situation. Flexion responses were considerably increased from baseline, muscle power in the involved extremity was strengthened, and there was generalization of responding from the laboratory to activities of daily living. It is concluded that motor return in hemiplegia can occuras late as 6 months post-brain injury if appropriate modification procedures are employed.

Studies conducted over the years in which the functional motor return of hemiplegics has been investigated have been concerned with neurophysiological changes (Twitchell, 1951), learning of simple tasks (Van Buskirk, 1954), motion at the joints (Bard \& Hirschberg, 1965), and the performance of daily activities (Carroll, 1967). These investigations have involved the observation of this return without attempting to modify its rate or topology through experimental manipulation of the actual critical response. The present study represents an attempt to influence the motor return directly in the involved upper extremity of individuals who have sustained a cerebrovascular accident.

The techniques employed were escape and avoidance conditioning, as they have been demonstrated to be effective with both animal and human Ss, with a variety of responses. In addition, since hemiplegic patients generally have sensory losses in the affected extremities, these methods appeared appropriate for this population, as work has been done conditioning responses in the deafferented limbs of monkeys (Taub \& Berman, 1963; Taub, Bacon, \& Berman, 1965).

\section{SUBJECTS}

Three patients, one female and two males aged 67,41 , and 58 years, respectively, with left hemiplegia resulting from a cerebrovascular accident (CVA), acted as Ss. The female $S$ (F-1) had sustained a CVA 6 months prior to experimentation; the two male Ss (M-1 and M-2) had CVAs which occurred 9 months and 10 months, respectively, prior to the study.

All Ss were given a neurological examination before the research was begun, ${ }^{1}$ and all were judged to have nonfunctional left upper extremities. S F-1 indicated shoulder elevator and rotator muscles at grade trace, and shoulder abductor, flexor, and extensor at grade zero. Both Ss $M-1$ and $M-2$ graded zero on all muscle tests, and both had severe spasticity in the left arm.

\section{APPARATUS AND PROCEDURE}

An initial baseline of elbow flexion was obtained for all Ss. Since elbow flexion is a relatively gross and simple response, and is easier for the hemiplegic to execute than finer movements, this was felt to be an appropriate response to attempt to modify in an initial study. Over a period of 50 sessions, lasting $15 \mathrm{~min}$ each, no $\mathrm{S}$ was able to voluntarily make a single elbow flexion. Then the Ss were randomly assigned to either escape or avoidance conditions. Ss F-1 and $M-1$ received escape conditioning treatment, while avoidance conditioning was employed with S M-2.

In both conditions of the experiment the forearm of each S's nonplegic upper extremity was held immobile by taping it to the arm of the wheelchair. To this forearm were at tached two copper electrodes, one on the above and one on the under side of the forearm. The forearm was lightly rubbed with sandpaper to decrease skin resistance, and the electrodes were lightly sheathed in thin canvas that had been soaked in saline solution. The plegic upper extremity was positioned on a wooden board that was clamped to the other arm of the wheelchair, remaining free to move. Attached to this board by a wingnut was a wooden arm that could be raised or lowered to any desired degree by the E. On the end of this arm was mounted a microswitch.

In the escape situation, the $S$ received an electric shock to the forearm of the nonplegic upper extremity which could be terminated only by a flexion response of the plegic arm so that his hand hit the microswitch that turned off the current. The shock was presented for a $10-$ sec period. If $S$ did not respond within this time the shock terminated automatically and remained off for $5 \mathrm{sec}$. The current intensity varied per session for $S \mathrm{M}-1$ from 2.5 to $3.4 \mathrm{~mA}$, and 
Table 1

Mean Responses of F-1 per Experimental Session

\begin{tabular}{|c|c|c|c|c|}
\hline Sessions & Trials & $\begin{array}{l}\text { Mean } \\
\text { Degrees } \\
\text { Flexion }\end{array}$ & $\begin{array}{l}\text { Frequency } \\
\text { Response } \\
\text { Emitted } \\
\end{array}$ & $\begin{array}{l}\text { Current } \\
\text { Level } \\
\text { (In mA) }\end{array}$ \\
\hline 1 & 60 & 0 & - & 2.5 \\
\hline 2 & 60 & 11.5 & 6 & 2.5 \\
\hline 3 & 60 & 23 & 5 & 3.1 \\
\hline 4 & 45 & 39 & 9 & 2.5 \\
\hline 5 & 40 & 30 & 14 & 3.0 \\
\hline 6 & 40 & 35 & 19 & 3.2 \\
\hline 7 & 40 & so & 12 & 3.2 \\
\hline 8 & 30 & 40 & 7 & 3.2 \\
\hline 9 & 60 & 45 & 10 & 3.1 \\
\hline 10 & 100 & 45 & 8 & 3.1 \\
\hline 11 & 100 & 40 & 4 & 3.2 \\
\hline 12 & 100 & 40 & 5 & 3.2 \\
\hline 13 & 100 & 40 & 5 & 3.2 \\
\hline 14 & 100 & 60 & 4 & 3.2 \\
\hline 15 & 100 & 50 & 4 & 3.0 \\
\hline 16 & 100 & 60 & 3 & 3.0 \\
\hline 17 & 100 & 70 & 4 & 3.1 \\
\hline 18 & 100 & 70 & 4 & 3.0 \\
\hline 19 & 100 & 70 & 5 & 3.0 \\
\hline 20 & 100 & 60 & 7 & 3.0 \\
\hline 21 & 100 & 70 & 6 & 3.0 \\
\hline 22 & 100 & 50 & 7 & 3.0 \\
\hline 23 & 100 & 45 & 6 & 3.0 \\
\hline 24 & 100 & 40 & 6 & 3.2 \\
\hline 25 & 100 & 45 & 7 & 3.2 \\
\hline
\end{tabular}

for S F-1 from 2.5 to $3.2 \mathrm{~mA}$. In the avoidance condition, $S M-2$ was presented with a brief click $5 \mathrm{sec}$ before the onset of the shock. By making a flexion response between click and shock he could postpone the onset of the shock for 10 sec. S M-1 received a current intensity that varied per session from 2.5 to $3.4 \mathrm{~mA}$. All shock was delivered from a standard chronaxie apparatus.

All Ss were begun at $5 \mathrm{deg}$ of elbow flexion and proceeded to greater or fewer degrees depending upon their responding. That is, the wooden arm with the microswitch was set so that it required a flexion response by $S$ of $5 \mathrm{deg}$ to hit the switch and thus terminate or postpone the shock. If an $\mathrm{S}$ was able to make this response 10 times consecutively, the arm was raised by 5 deg until the response had been made at that level and was raised thereafter in successive 5-deg units. If $S$ was unable to make the desired response, the arm was lowered to a position where responding was possible and advanced from that point. If no remarkable response increases from baseline were seen within 20 experimental sessions, the procedure was terminated. Each experimental session was of $15 \mathrm{~min}$ duration.

\section{RESULTS}

Neither S M-1 nor S M-2 was able to make any significant elbow flexions within 20 sessions, and the procedure with them was terminated.

Notable changes were seen for S F-1 who was in the escape situation. The data for $\mathrm{S} \mathrm{F-1} \mathrm{are} \mathrm{presented} \mathrm{in} \mathrm{Table} 1$. On the first day she was able to flex her elbow to $22 \mathrm{deg}$, with a mean of $11.5 \mathrm{deg}$ for 60 trials. She continued to progress from there, averaging up to $70 \mathrm{deg}$ of flexion for 10 trials on four separate occasions. Her performance was inconsistent and varied between a mean of $40 \mathrm{deg}$ and a mean of $70 \mathrm{deg}$ for the last 19 sessions. Her responses included shoulder elevation as well as elbow flexion, but were primarily true critical responses. Neuro. logical examination following conclusion of the study revealed the following changes: shoulder elevator muscles graded fair-minus; shoulder abductor muscles graded tracepoor-minus; shoulder rotator, flexor, and extensor muscles graded trace; and elbow flexor muscles graded trace. All were improvements over her status prior to the experimentation. In addition, the patient was able to move her affected upper extremity voluntarily outside of the laboratory setting, which was previously impossible for her to do.

\section{DISCUSSION}

As has been previously noted, studies in the past which have been concerned with motor return in hemiplegic patients have been restricted to observation rather than experimental manipulation. Van Buskirk (1954) reported that return of function appears to be a spontaneous process and that the first 2 months following a CVA are crucial. Bard \& Hirschberg (1965), in a study of 116 patients, found that all who regained full motion in their hemiplegic arms had initial motion within the first month following the stroke. Carroll (1967) observed the rate of return in 48 patients and concluded that unless there is evidence of hand movement within 2 weeks postCVA, there will be no significant return of upper extremity function.

The present study was an attempt to demonstrate that operant conditioning could directly affect motor return in hemiplegia. The Ss all had sustained the cerebral injury at least 6 months prior to their participation in the research. S M-1 and S M-2 had marked spasticity in their plegic arms, yet SM-1 did evidence some very slight increase in muscle power. The $S$ for whom notable results were obtained, not only increased muscle strength considerably, but became able to voluntarily use the involved arm as an assist in some tasks for her nonplegic arm. Prior to the study, the plegic upper extremities of all Ss were totally nonfunctional.

It appears, then, that while the results obtained are not of great magnitude, they are encouraging and point up the fact that motor return in hemiplegia can occur as late as 6 months following initial brain damage if appropriate modification procedures are employed.

\section{REFERENCES}

BARD, G. \& HIRSCHBERG, G. G. Recovety of voluntary motion in upper extremity following hemiplegia. Archives of Physical Medicine \& Rehabilitation, 1965, 46, 567-572.

CARROLL, D. Return of upper extremity function in hemiplegia. Maryland State Medical Journal, 1967, 16, 129-131.

TAUB, E., BACON, R. C., \& BERMAN, A. J. Acquisition of a trace-conditioned avoidance response af ter deafferentiation of the responding limb. Journal of Comparative \& Physiological Psychology, 1965, 59, 275-279.

TAUB, E. \& BERMAN, A. J. Avoidance conditioning in the absence of relevant proprioceptive and exteroceptive feedback. Journal of Comparative \& Physiological Psychology, 1963,56, 1012-1016.

TWITCHELL, T. E. The restoration of motor function in man. Brain, 1951,74, 443-480.

VAN BUSKIRK, C. Return of motor function in hemiplegia. Neurology, 1954, 4, 919-928.

$$
\text { NOTE }
$$

1. The author is indebted to M. Menon for the neurological evaluations. 